\title{
The impact of AIDS in the pediatric and adolescent populations
}

\author{
ANTHONY H. DEKKER, DO
}

\section{Although pediatric and} adolescent AIDS cases comprise only $1.9 \%$ of the national total AIDS population, the numbers are increasing rapidly. As there appears to be no effective treatment for these patients, an aggressive preventive approach is needed. Pediatric AIDS diagnosis and symptomatology differ from the adult population. Vaccination protocols for symptomatic HIV-infected children differ from their uninfected peers.

Adolescent issues of sexual activity, sexual exploitation, and chemical abuse raise the probability of spread in this population.

Issues surrounding the human immunodeficiency virus (HIV) and its resultant medical problems have become primary sources of concern for most health-care providers as well as for society in general. Most physicians have become very aware of the basic issues that concern the adult HIV-infected population. However, few think that they will have significant contact with HIV infections in the pediatric and adolescent populations.

The purpose of this article is to sensitize the physician and other health-care workers to the prevalence, problems, complications, and, particularly, to the emotional aspects of HIV infections in the child and adolescent. According to the Centers for Disease Control, ${ }^{1}$ as of Jan 18, 1988 , a total of 51,361 cases of acquired immunodeficiency disease (AIDS) had been confirmed; 778 of these involved children between the ages of $0-13$ years, and 218 occurred in adolescents aged 13 to 19 years. Although these pediatric and adolescent AIDS populations comprise only $1.9 \%$ of the total number of persons with AIDS, they are growing at a faster rate than the adult population. During the five months preceding the January count, the total number of AIDS patients increased by approximately $25 \%$, while the number of adolescent AIDS cases increased by $101 \% .{ }^{1}$ The pediatric rate of increase was $39 \%$ for the same period. ${ }^{1}$

According to Oleske, ${ }^{2}$ "Estimates from the CDC suggest that by 1991 there will be 12.5 million Americans infected with AIDS virus, and 250,000 of these will be symptomatic AIDS cases. Based on our experience and those of others caring for pediatric cases, by 1991 there may be 10,000 to 20,000 symptomatic-HIV infected infants and children in the USA."

Basic issues of adolescent behavior and sexual practices that contribute to the continued spread of this disease are discussed in the article. Although disturbing, prostitution is not an uncommon situation in the adolescent population. In fact, there are more than 300,000 male and 600,000 female adolescent prostitutes in this country. ${ }^{3} \mathrm{~A}$ moving story by a mother ${ }^{2}$ whose 3 -year-old son died from AIDS is included and begins on page 641 .

\section{Physician responsibilities}

As with any other disorder, three areas of responsibility are in the physician's domain. Prevention and education, appropriate diagnosis, and treatment consistent with present standards must be adhered to in AIDS, as in all diseases.

\section{Prevention and education}

AIDS has now reached its exponential growth curve, and we must, as a profession, educate not only ourselves but also health care personnel with whom we work. Public education for our patients and community must be provided. Despite immense 
amounts of information available to the professional and lay populations, misconceptions concerning AIDS thrive. The educational challenge is difficult but addressable. (In an article that also is published in this issue of JAOA, page 634, William $\mathrm{Kane}, \mathrm{PhD}$, discusses physician participation in the education of students about AIDS.)

Misunderstandings and lack of education in professional populations also are common. The mother's story mentioned previously identifies the tremendous stress a family must endure when a child has AIDS. Many of the conflicts she encountered were directly related to misconceptions by health-care, mortuary, insurance, and various other professionals. In 1987, you will remember, the three Ray children of Arcadia, Florida, experienced extreme prejudice and violence secondary to community paranoia. Their transfusion-acquired disorder resulted in termination of their rights to attend school and church, and, finally, in their home being burned down.

On the other hand, there have been numerous instances of exemplary behavior by local educators, school boards, clergy, and professionals across this country. All of these resulted from educational intervention to the community at large. Table 1 presents the national PTA's 1986 resolution ${ }^{4}$ regarding school children with AIDS.

\section{Diagnosis}

Although serologic testing for HIV antibodies has been made possible through the ELISA and Western blot methods, group screening of the pediatric population is not recommended. There should, however, be a vigorous expansion of HIV antibody testing, always within the context of confidentiality, voluntary informed consent, and pre- and post-test counseling, in high-risk patient populations.

Children with parents who are at high risk obviously should be tested, as should children who have received any blood products from 1979 to the present time. Also, children who have been sexually abused should be monitored closely for seroconversion. In one case, ${ }^{5}$ a 5 -year-old boy developed AIDS after repeated sexual abuse by his AIDSstricken father. Other obvious or bizarre situations should be explored; for example, a 7-year-old girl developed ARC following intravenous drug injections by family members. ${ }^{5}$

The distribution of pediatric AIDS cases by the type of transmission is presented in Table $2 .{ }^{6} \mathrm{Com}$ mon clinical signs and symptoms of pediatric HIV infection and their incidences are as follows ${ }^{7}$ : lymphadenopathy $(90 \%)$, hepatomegaly $(86 \%)$, splenomegaly $(69 \%)$, failure-to-thrive $(62 \%)$, thrush and candidal skin infections (48\%), upper respiratory tract infection and otitis media $(45 \%)$, parotitis or salivary gland enlargement (10\%), and Kaposi's sarcoma (1\%).

Although there are similarities between pediatric and adult HIV disorders, there also are significant differences. Polyclonal hypergammaglobulinemia is far more pronounced in children. HIV dysmorphism most likely occurs because of this disorder's effects on the growth centers. Progressive neurologic disorders secondary to primary HIV CNS infections are more serious in the pediatric population. ${ }^{8}$ They include significant developmental delay in all areas of gross and fine motor, personal, social, and language development. There have also been increased reports of seizure disorders, perceptual motor dysfunction, encephalopathies, and abnormal structural findings, such as cortical atrophy and intracranial calcification.

Opportunistic infections in children also present differently than in adult AIDS (Table 3). ${ }^{9}$ Kaposi's sarcoma and B-cell lymphomas are rare in children, while lymphoid interstitial pneumonitis is observed more frequently in the pediatric population. Hepatitis-B virus infection occurs less frequently in the pediatric population, but bacterial infections with septicemia present a more serious problem in children.

In evaluating pediatric patients with immunologic disorders, it is important to distinguish between primary immune deficiencies and HIV infections. The following appear to be unique to HIV infections ${ }^{10}$ : polyclonal hypergammaglobulinemia; depressed T-lymphocyte helper: suppressor ratio; absolute decrease in T-helper cell's; decreased or absent peripheral blood mononuclear cells; response to mitogen, antigen, and alloantigen; and severe depletion of lymphocytes and Hassall's corpuscles in the thymus.

The presence of $\mathrm{HIV}$ antibody in infants younger than 6 months does not indicate active infection; the IgG antibody most likely is secondary to transplacental passage. Laboratory evaluation for IgM antibody is yet to be perfected. When it becomes available, it will be very helpful to identify active infection in infants. It is suspected ${ }^{8}$ that an inability to mount an IgM response may be secondary to active HIV infection and subsequent immune suppression.

All children who are being evaluated for HIV infection require at least the following laboratory studies: complete blood count, quantitative immunoglobulin assays, liver function evaluation, and HIV antibody testing by the ELISA procedure and confirmation with the Western blot method. Nearly all HIV-infected children are anemic and have ele- 
vated liver enzyme values. The criteria for laboratory evidence for or against HIV infection is presented in Table $4 .^{11}$ Chest x-rays also should be obtained. Definitive diagnostic procedures for diseases associated with AIDS are delineated in Table $5 .{ }^{12}$

\section{Treatment}

After AIDS is diagnosed and the stage of the disease has been determined according to CDC protocol, ${ }^{13}$ treatment should be instituted. At Newark Children's Hospital of New Jersey ${ }^{14}$ in Newark, AIDS patients have been treated preventively with intravenous gamma globulin, which has resulted in a decrease in mortality of about $35 \%$ over a specified time. These authors also report a decrease in recurrent septic episodes (from $45 \%$ in 1983 to $5 \%$ in 1986).

It appears that primary HIV infections affect not only the immune system, but also the CNS, the heart, the kidneys, and the liver. The greatest challenge in treatment, however, continues to lie in devising therapeutic programs for opportunistic infections and malignancies.

At the present time, the treatment of Pneumocystis carinii pneumonia is with trimethoprim-sulfamethoxazole or pentamidine, or both. There seems to be lack of response in many children treated with trimethoprim-sulfamethoxazole. ${ }^{9}$ Therefore, further evaluation of aerosolized pentamidine and other agents of the dihydrofolate reductase antagonist class is needed. Prophylactic therapy to exposed high-risk children also needs to be explored. Candidal infections that are systemic require aggressive therapy. This may include toxic medications, such as amphotericin B and other imidazoles. Treatment of lymphoid interstitial pneumonia continues to be a major problem. Further evaluation of combined therapies with steroids and specific antiviral agents is necessary. It should be noted that indiscriminate use of antibiotics always is discouraged. However, wellplanned studies incorporating antibiotic prophylaxis should be pursued.

The question of immunizations for HIV-positive and HIV-antibody-positive children has been discussed at length..$^{15}$ At the present time, inactivated antigens, such as DPT, DT, dT, pneumococcus, and Hemophilus influenza type B vaccines, should be provided at age-appropriate intervals (as in the noninfected pediatric populations). The attenuated measles vaccine also is recommended for asymptomatic HIV-positive children.

The consensus opinion, however, is that symptomatic HIV-positive children should not receive live virus vaccines..$^{15}$ It is also thought that chil-
TABLE 1. RESOLUTION* OF NATIONAL PTA REGARDING SCHOOL CHILDREN WITH ACQUIRED IMMUNODEFICIENCY SYNDROME. 4

Resolved, That the National Congress of Parents and Teachers believe that in the case of diagnosed Acquired Immunodeficiency Syndrome, the child's physician, public health officials, the parents or guardians of the child, and the appropriate school personnel should be responsible for determining the most suitable placement for that public school child; and be it further

Resolved, That the National Congress of Parents and Teachers discourage social displays that seek to segregate, persecute, or ban children with AIDS from school.

*Adopted by 1986 convention delegates.

\begin{tabular}{|c|c|c|}
\hline Type of transmission & No. & Percent \\
\hline Hemophilia & 18 & 5.1 \\
\hline $\begin{array}{l}\text { Mother practicing intravenous } \\
\text { drug abuse }\end{array}$ & 162 & 46.3 \\
\hline $\begin{array}{l}\text { Mother with bisexual male } \\
\text { sex partner }\end{array}$ & 13 & 3.7 \\
\hline $\begin{array}{l}\text { Mother whose male sex partner } \\
\text { was intravenous drug abuser }\end{array}$ & 38 & 10.9 \\
\hline $\begin{array}{l}\text { Mother with unknown risk factor } \\
\text { who was HIV seropositive }\end{array}$ & 11 & 3.1 \\
\hline Blood transfusion & 49 & 14.0 \\
\hline Undetermined cause & 10 & 2.9 \\
\hline $\begin{array}{l}\text { Mother or father acquired HIV } \\
\text { by transfusion }\end{array}$ & 6 & 1.7 \\
\hline Mother born in country outside & & \\
\hline $\begin{array}{l}\text { United States } \\
\text { Total }\end{array}$ & $\frac{43}{350}$ & $\frac{12.3}{100.0}$ \\
\hline
\end{tabular}

TABLE 3. OPPORTUNISTIC INFECTIONS ASSOCIATED WITH AIDS IN THE PEDIATRIC POPULATION. ${ }^{9}$

\begin{tabular}{|lr|}
\hline Diagnosis & $\begin{array}{r}\text { Percent } \\
\text { of cases }\end{array}$ \\
\hline Pneumocystis carinii pneumonia & $53-64$ \\
Lymphoid interstitial pneumonia & $17-45$ \\
Candida (thrush esophagitis or pulmonary disease) & 11 \\
Mycobacterium avium-intracellulare & $7-10$ \\
Cytomegalovirus (disseminated) & $9-16$ \\
Cryptosporidiosis & $5-6$ \\
Herpes simplex virus (chronic) & $4-6$ \\
Primary lymphoma of brain & 2 \\
Cryptococcal meningitis & 1 \\
\hline
\end{tabular}

dren who are HIV positive who have been exposed to measles should receive gamma globulin. Those exposed to varicella should receive varicella zoster immune globulin..$^{15}$ Those with varicella should be treated with acyclovir therapy. ${ }^{15}$ It should also be noted that children with major viral illnesses who are HIV positive seem to be extremely susceptible to bacterial superinfections. ${ }^{14}$ As for all children with chronic illness, nutrition and growth must be monitored carefully. Developmental milestones should be checked (by using the Denver Developmental Screening Test) on a regular basis for chil- 
TABLE 4. LABORATORY EVIDENCE FOR OR AGAINST HIV INFECTION. ${ }^{11}$

(1) For infection:

When a patient has disease consistent with AIDS:

(a) a serum specimen from a patient $\geqslant 15$ months of age, or from a child $<15$ months of age whose mother is not thought to have had HIV infection during the child's perinatal period, that is repeatedly reactive for HIV antibody by a screening test (for example, enzymelinked immunosorbent assay [ELISA]), as long as subsequent HIV-antibody tests (for example, Western blot, immunofluorescence assay), if done, are positive; or

(b) a serum specimen from a child $<15$ months of age, whose mother is thought to have had HIV infection during the child's perinatal period, that is repeatedly reactive for HIV antibody by a screening test (for example, ELISA), plus increased serum immunoglobulin levels and at least one of the following abnormal immunologic test results: reduced absolute lymphocyte count, depressed CD4 (T-helper) lymphocyte count, or decreased CD4/CD8 (helper/suppressor) ratio, as long as subsequent antibody tests (for example, Western blot, immunofluorescence assay), if done, are positive; or

(c) a positive test for HIV serum antigen; or

(d) a positive HIV culture confirmed by both reverse transcriptase detection and a specific HIV-antigen test or in situ hybridization using a nucleic acid probe; or

(e) a positive result on any other highly specific test for HIV (for example, nucleic acid probe of peripheral blood lymphocytes).

(2) Against infection:

A nonreactive screening test for serum antibody to HIV (for example, ELISA) without a reactive or positive result on any other test for HIV infection (for example, antibody, antigen, culture), if done.

(3) Inconclusive (neither for or against infection):

(a) a repeatedly reactive screening test for serum antibody to HIV (for example, ELISA) followed by a negative or inconclusive supplemental test (for example, Western blot, immunofluorescence assay) without a positive HIV culture or serum antigen test, if done; or

(b) a serum specimen from a child $<15$ months of age, whose mother is thought to have had HIV infection during the child's perinatal period, that is repeatedly reactive for HIV antibody by a screening test, even if positive by a supplemental test, without additional evidence for immunodeficiency as described above (in $1 \mathrm{~b})$ and without a positive HIV culture or serum antigen test, if done.

dren younger than 6 years.

There may be circumstances that would warrant reverse isolation of an HIV-positive child. School outbreaks of measles, chicken pox, or mumps may require the child to be tutored at home until the acute infections are ended. Emotional responses to this vulnerability may be varied. Some children may become depressed because of their powerlessness, while others may begin "acting out" behavior.

In addition to comprehensive medical services, multidisciplinary assessment for all children with HIV infections must be provided. This should be provided by psychologic, social service, child life
TABLE 5. DEFINITIVE DIAGNOSTIC METHODS FOR DISEASES INDICATIVE OF AIDS, 12

Disease Definitive diagnostic methods

Cryptosporidiosis

Cytomegalovirus

Isosporiasis

Kaposi's sarcoma

Lymphoma

Lymphoid pneumonia Microscopy (histology or cytology) or hyperplasia

Pneumocystis carinii pneumonia

Progressive multifocal leukoencephalopathy

Toxoplasmosis

Candidiasis

Gross inspection by endoscopy or autopsy or by microscopy (histology or cytology) on a specimen obtained directly from the tissues affected (including scrapings from the mucosal surface), not from a culture

Coccidioidomycosis

Cryptococcosis Microscopy (histology or cytology), culture, or detection of antigen in a

Herpes simplex virus specimen obtained directly from Histoplasmosis the tissues affected or a fluid from those tissues

Tuberculosis

Other mycobacteriosis

Salmonellosis

Other bacterial

infection therapy, nutrition, and developmental personnel. Frequent staff meetings to review treatment plans for these children must be conducted; the physician should play an important role in these sessions.

\section{Special considerations for adolescents}

Keeping in mind that $50 \%$ of all sexually transmitted diseases occur during the adolescent years, and that $75 \%$ of all reported sexually transmitted diseases occur between the ages of 15 and 24, the AIDS epidemic most likely will have significant ramifications in the adolescent and young adult populations. ${ }^{16}$ The disease itself, however, seems to have significantly different etiologies in the adolescent versus the pediatric populations. Because the mortality rate for pediatric AIDS is so high $(60 \%),{ }^{17}$ the likelihood of a child surviving from infancy to adolescence with an HIV infection is small. It appears that most adolescents with AIDS contracted the infection during their teenage years.

At present, there are very few studies that identify etiologies in adolescent $\mathrm{HIV}$-infected individuals. In the Adolescent Program of Chicago Osteopathic Medical Center, we now have 20 patients who are HIV antibody positive. We have seven adolescent patients who have AIDS or ARC, as determined by the revised CDC protocol; five admit to 
intravenous drug abuse and two admit to multiple homosexual contacts, with no other risk factors. One of the female intravenous drug abusers also is a prostitute; she reports having contact with more than 1,000 male clients. Two other intravenous drug-abusing patients admit to male prostitution on a regular basis.

Some have hypothesized that the AIDS hysteria has contributed to a decrease in sexual activity in adolescents and young adults. Unfortunately, this has not been observed in many populations, including ours. Many teenagers feel omnipotent and believe that it is their responsibilty to have as many experiences as possible during their adolescence. Experimenting in various sexual practices and in chemical abuse are unfortunately the rule rather than the exception.

Of the 29 million adolescents over 12 years of age, 12 million are sexually active. Sixty-seven percent of all sexually active adolescents do not routinely use contraceptives. And, only $14 \%$ of sexually active adolescents use condoms regularly. ${ }^{19}$

There have been excellent examples of appropriate interventions to decrease the risk of HIV transmission in adolescent populations in Swiss teens ${ }^{20}$ and San Francisco. ${ }^{21}$ (Similar interventions are described in Dr Kane's article beginning on page 634.)

Johnston ${ }^{9}$ recently reported that $58 \%$ of high school seniors admitted that they had used an illicit drug and $80 \%$ of young adults in their mid20 s admitted to have used one in the past. Seventeen percent of high school seniors and $40 \%$ of young adults have used cocaine. Specific data concerning intravenous drug abuse by adolescents are unknown, but it is estimated that approximately 4 to $5 \%$ of the adolescent population has experimented with intravenous drug administration for nonmedicinal purposes. ${ }^{22}$

\section{Adolescent emotional considerations}

We have experienced and there have been numerous reports from other centers that adolescent behavior may deteriorate precipitously upon learning of an AIDS infection. ${ }^{23}$ Three of our seven patients made threats to "spread this infection as much as possible" after being told of the need to stop their risky behavior. Increased sexual promiscuity and other malicious intents to spread HIV infections also are reported from other metropolitan programs. ${ }^{24}$ In one case, we have sought criminal charges against an adolescent who stated that he wished to infect others with the HIV virus purposely. No doubt any such active process must be preceded by legal counsel and social service and psychologic assessments.
1. AIDS Weekly Surveillance Report, Center for Infectious Diseases, Center for Disease Control, Atlanta, Jan 18, 1988.

2. Oleske J: Report of the Surgeon General's Workshop on Children with HIV Infections and Their Families. US Dept of Health and Human Services publication No. HRS-D-MC-87-1, April 1987, pp 24-25, 48-50.

3. Deisher R, Robinson G, Boyer D: The adolescent female and male prostitute. Pediatr Ann 1982;819-825.

4. National PTA 1986 Convention delegates. Resolution on Acquired Immunodeficiency Syndrome, 1986, National PTA Association, Chicago.

5. Rubinstein A, Bernstein L: The epidemiology of pediatric acquired immunodeficiency syndrome. Clin Immunol Immunopathol 1986;40:115121.

6. Acquired Immunodeficiency Syndrome (AIDS) among blacks and Hispanics-United States. MMWR 1986;35:655-666.

7. Pahwa S, Kaplan M, Firkrig S, et al: Spectrum of human T-cell lymphotropic virus type III infection in children: Recognition of symptomatic, asymptomatic and seronegative patients. JAMA 1986;255:22992305 .

8. Laurence J: HIV infections in infants and children. Infectious Med Feb 1987, pp 44-56.

9. Rubinstein A, Moreck R, Silverman B, et al: Pulmonary disease in children with acquired immunodeficiency syndrome and AIDS-related complex. J Pediatr 1986;108:498-503.

10. Amman AG, Kaminsky L, Conan M, et al: Antibodies to AIDSassociated retrovirus distinguish between pediatric primary and acquired immunodeficiency diseases. JAMA 1985;253:3116-3118.

11. Laboratory evidence for or against HIV infection. MMWR $1987 ; 10 \mathrm{~S}$. 12. Definitive diagnostic methods for diseases indicative of AIDS. MMWR $1987 ; 11$ S.

13. 1987 Revision of case definition for AIDS for surveillance purposes. MMWR 1987;1S-9S.

14 Pediatric AIDS conference: Treatment of infants with AIDS, Marathon, Fla, Nov 16, 1984.

15. ACIP: Immunization of children infected with human T-lymphotropic virus type III//ymphadenopathy-associated virus. MMWR 1986;35:595606.

16. Silber TJ, Woodward K: Sexually transmitted diseases in adolescence. Pediatr Ann 1982;11:10.

17. Koop CE: Keynote address: Report of the Surgeon General's Workshop on Children with HIV infections and their families. US Public Health Service, US Dept of Health and Human Services, Publication No. HRSD-Mc, 87-1, April 1987, p 3.

18. Johnston L, Buchman JB, O'Malley PM: Monitoring the future. Institute for Social Research, University of Michigan/National Institute on Drug Abuse. US Government Printing Office, 1987.

19. Alan Guttmacher Institute: Teenage Pregnancy: The problem that hasn't gone away. The Guttmacher Institute, New York, 1981.

20. Michand PA: Presentation and evaluation of an AIDS and STD prevention program for Swiss teenagers. Annual research meeting of the Society for Adolescent Medicine, New York, March 27, 1988.

21. Irwin C, Muscieki B, Millstein S, et al: Adolescent beliefs and behaviors concerning sexually transmitted disease and acquired immunodefi. ciency syndrome. Annual research meeting for the Society for Adolescent Medicine, New York, March 27, 1988.

22. National Institute for Drug Abuse, Information, Washington, DC, 1987.

23. Jaffe L, Aledort L: Adolescents with hemophilia: Psychological and sexual implications of infection with the human immunodeficiency virus. Annual research meeting of the Society for Adolescent Medicine, New York, March 27, 1988.

24. D'Alonzo, G: General precautions for medical professionals. AIDS: The dilemma of the eighties. University of Osteopathic Medicine and Health Sciences, Nov 12, 1987.

From the Division of Community Medicine, Department of Family Medicine, Chicago College of Osteopathic Medicine, Chicago, Ill.

Reprint requests to Dr Dekker, CCOM, 5200 S Ellis Ave, Chicago, IL 60615 . 